\title{
Book Reviews / Comptes rendus
}

Clark, Ian D., Moran, Greg, Skolnik, Michael L., and Trick, David. (2009). Academic Transformation: The Forces Reshaping Higher Education in Ontario. Montreal and Kingston; Queen's Policy Studies Series, McGill-Queen's University Press. Pages: 250. Price: 39.95 CAD (paper).

Reviewed by Julian Weinrib, PhD Candidate, OISE, University of Toronto.

Academic Transformation: The Forces Reshaping Higher Education in Ontario leaves the reader in a somewhat ambiguous and uncertain position; at once both confident in, and mystified by, the functionally chaotic history of Ontario's post-secondary system, but simultaneously doubtful of the systems' ability to negotiate modern threats in its cumbersome two-pronged structure of relatively undifferentiated universities and colleges.

On the first page of the introduction, the authors put forward their operational thesis that "the present approach to the provision of baccalaureate education in Ontario is not sustainable and is in need of significant modification" (p. 1). In this section, the stage is set for the book's thorough investigation of the historical and contemporary contexts that have produced the system's tensions: 1) an overview of the Ontario context in the early stages of the $21^{\text {st }}$ century; 2) implications of the move from elite to mass to near-universal access; 3 ) the rise and impact of the knowledge economy and a new research paradigm; 4) historical shifts in funding patterns; 5) the impact of quality and accountability regimes; and finally, 6) Ontario's systemic design.

Intending to analyze roughly 50 years of system development along six different trajectories in just over 200 pages, the authors set out an ambitious roadmap that threatens to reduce a potentially fruitful, in-depth analysis of the current situation into a generic recitation of historical events and policies. Fortunately for the reader, in drawing from their vast array of professional, institutional and systemic experiences, the four authors weave an insightful narrative of both federal and provincial post-secondary systems and policies in support of their argument that Ontario's system is on the edge of a precipice. While at times straying far into the historical record in an effort to paint a full picture of the broad Canadian context, they manage to stay true to the central message that the current Ontario system is rife with tensions, ambiguity and uncertainty. 
One limitation of their approach, to be elaborated upon below, is that the rich historical description only selectively leads to pragmatic prescriptions for future transformation, undercutting the analytic potential of the project.

While there are many conceptual and structural issues raised of varying degree and severity, the authors choose to focus on a few that they deem to be the most significant: a lack of systemic differentiation at both the university and college levels, the inadequacy of the teacher-researcher faculty equation in the era of global competition and skyrocketing demand, and the repercussions of Canada's fragmented federal and provincial policy mechanisms. The latter proves to be the most engaging investigation of how external forces are reshaping the Ontario landscape. The authors explicate how new federal research funding initiatives that circumvent issues of provincial jurisdiction, such as the Canadian Centres of Excellence, the Canadian Foundation for Innovation, and the Canada Research Chair program to name a few, are emblematic of a new paradigm that ties institutional activities much closer to federal and privatesector priorities. The authors offer an excellent examination of the impact that this shift has had not only on the relationship of institutions to government and the private sector, but also on the internal dynamics of the institutions themselves. Their poignant analysis of the fragmentation of institutional administrative sub-structures and the significant impact on academic and institutional cultures forces the reader to question how well the new paradigm aligns with more holistic societal and government objectives of post-secondary education.

In general, it must be noted that many of the major arguments raised in the book are not new to the literature; critiques of the new research paradigm, the undifferentiated systemic design, and debates over quality assurance indicators and accountability mechanisms have all been at play in the Canadian literature for quite some time, not least of which through the previous writings of the four authors. However, the comprehensive presentation of the six major themes is an excellent contribution to readers seeking to gain a better understanding of the diverse issues facing the construction and re-construction of any jurisdictions' post-secondary system in the contemporary social, economic and political climate.

What is somewhat more problematic for this reader is the absence of a concise argument throughout the piece. The authors do well to place their thesis up front and make explicit claims about the tensions arising from the development of the current system, but the book as it is laid out results in two significant limitations to the criticality of the issue. First, there is at times only a broad linking of the six major themes to the initial claim of systemic un-sustainability, and second, there are few prescriptions or recommendations to make each theme actionable, until the final chapter when such prescriptions are presented only at the most general level.

The result of an overarching argument is the presence of six different narratives that greatly vary in their cohesiveness until the final summative chapter and fail to create a strong linking meta-narrative. The final chapter summarizes 
the major findings and integrates them into suggestions for systemic and institutional reformations, but it does so in very broad and somewhat idealistic terms that fail to critically engage the important findings raised throughout the book. For instance, Chapter 5 gives an excellent account of the historical use of quality assurance measures, indicators and discourses in Ontario's post-secondary system over the past 40 years, yet in conjunction with the final chapter only limited prescriptions are offered as to how the system can or should be changed. The broadly titled one page summary in Chapter 7, "Rethinking the Idea of Quality in Higher Education," presents only a barebones description of the problem and doesn't engage the reader in constructive analysis as anticipated.

This is not to say that the book offers limited prescriptions, but rather, the authors are very selective in their critical engagement, such that some topic are dealt with broadly and others somewhat more ad hoc. For example, page 180 offers a list of the "Characteristics of an Ideal Post-Secondary System for Ontario," highlighted by bullet points such as, "more accessibility: a higher participation rate of traditionally under-represented groups," and "incentives for innovation in teaching techniques and student support". While these points are absolutely crucial to the often-raised issue of engaging Ontario's societal objectives for the post-secondary education, there is limited analytic space given to these items throughout the book. This is particularly apparent when it comes to the issue of access for under-represented groups, a topic that is noticeably given little critical analysis in the chapter on access, particularly in regards to the complex issue of Aboriginal students, which receives less than a page of reflection (see p. 36). This can perhaps be accounted for by the far-reaching and ambitious framework of the book, but the brevity and generality of such topics is noteworthy nonetheless given both the growing provincial drive to raise participation levels and the central role that access plays in the authors' thesis.

The result of this tension is that much of the book reads like a summative history of post-secondary education in Ontario and not as a roadmap for its potential transformation in light of the impending crises. In lieu of the title, Academic Transformation: The Forces Reshaping Higher Education in Ontario, too much emphasis seems to have been given to the shaping that has occurred to this point and not enough on how the academy can transform and reshape itself to better engage the 'forces' of the $21^{\text {st }}$ century. That being said, the book is a must-read for students and scholars of Canadian post-secondary education, as it gives a thorough and comprehensive description of the challenging realities faced by Canada's systems, institutions, programs, and individuals, and raises critical questions about what universities and colleges represent in our society. 